\title{
DISKURSUS ISLAM KONTEMPORER
}

\author{
Oleb: Yusdanidan M. Roem Syibli
}

\section{Abstract}

The research below tries to investigate the trend of Islamic discourse and writing structure of bulletins published every Friday in Yogyakarta Special Territory. The research constitutes descriptive and survey methods based on religiousity and sociological approaches. The data are obtained from six different bulletins namely al-Ikbtilaf, al-Rasikh, al I'tishom, al-Ikblas, at-Taubid, and Risalab Jumat. The result revealed that the bulletins distributed in Yogyakarta are generally categorized as substantive either in its paragraph, content, closing paragraph or in their Islamicity discourse.

يسعى هذا البحث إلى تقديم صورة معمقة عن المخطاب الإسلامي الخاص بالنشرات الصادرة يوم المجمعة في مدينة جو كجاكرتا-إندونيسيا، وذلك عبر دراسة نمط وهيكل النشاط الكتابي في هذه النشرات. يعتبر هذا

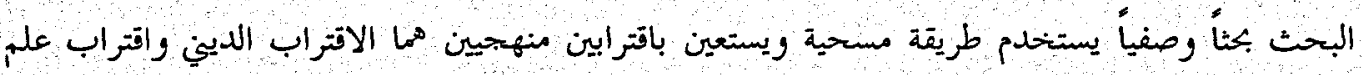
الاجتماع. لقد أجري البحث على عينة من ست نشرات صادرة في حوكحاكرتا وهي: الانتلاف

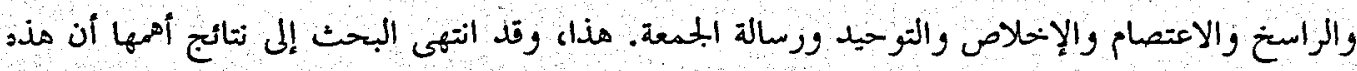
النشرات، من ناحية هيكلها تبدأ معدمة وتنتهي بخامة وفيما ييهما محتوى. ومن ناحية الخطاب الإسلامي الذي تعير عنه فإنه يككن وصفه بخطاب عصري يعبر عن محتوى إسلامي حقيقي

Keyreords: Buletin, Keislaman, Wacana

\section{A. Pendahuluan}

Setelah rejim otoriter Orde Baru lengser, Indonesia, negara yang berpenduduk mayoritas muslim, muncul tuntutan sangat kuat akan pengakuan indentitas agama, khususnya Islam. Hal ini ditandai dengan semaraknya dipergunakan kembali idiom

* Artikel ini adalah ringkasan hasil penelitian interdisipliner PSI UII yang didanai oleh DPPM UII tahun 2006/2007.

- Yusdani adalah dosen tetap FIAI UII dan peneliti pada PSI UII email:yusdani msi@yahoo.com dan M.Roem Syibli adalah peneliti pada PSI UII email: roems sib@yahoo.com. 
dan simbol-simbol Islam dan orientasi struktural dalam meng-Islamkan masyarakat, atau dalam bahasa Azyumardi Azra disebut sebagai Islam Politik. ${ }^{1}$

Selain itu, pergeseran iklim politik tersebut juga mempunyai implikasi pada pergeseran dinamika pemikiran Islam dan mobilitas wacana keagamaan yang berkembang dalam masyarakat. Karena itu, jika pada masa sebelumnya corak pemikian Islam hanya berkutat pada dikotomi santri pemurnian dan non-pemurnian, yang dalam tingkat tertentu adalah Muhammadiyah dan NU, namun sekarang telah terjadi fenomena baru, yaitu "santri baru".

Beberapa fenomena yang berkembang di kalangan santri baru yang dapat dikemukakan adalah:

Pertama, Islam Indonesia dikejutkan beberapa serangan bom, seperti yang terjadi di Bali dan Kedutaan Australia, Jakarta, dan sebagainya, oleh kalangan santri yang rata-rata masih muda dengan jargon jibad.

Kedua, fenomena ketika sebagian santri muda di Indonesia mendirikan organisasi berbasis kampus yang bernama KAMMI (Kesatuan Aksi Mahasiswa Muslim Indonesia), dan lebih dari itu KAMMI menerbitkan majalah Islam Sabili. ${ }^{2}$

Ketiga, munculnya anak-anak muda yang menamakan Islam Liberal, yang selanjutnya mendirikan JIL (Jaringan Islam Liberal).

Keempat, Islam Indonesia juga disemarakkan dengan munculnya wacana-wacana keagamaan yang berupaya mendekonstruksi pemahaman mapan atas teks-teks agama, seperti: wacana post tradisionalis, pembebasan kaum tertindas, dan seterusnya.

Kelima, Islam Indonesia juga digencarkan dengan munculnya kelompok-kelompok muda santri yang berusaha berbicara tentang Islam lokal, kesenian lokal, dan tentang format Islam moderat.

Munculnya fenomena adanya pergeseran wacana keagamaan tersebut juga terjadi di Yogyakarta. Hal ini terjadi mungkin karena di Yogyakarta terdapat berbagai perguruan tinggi, masyarakatnya lebih bersifat akademis dan terbuka, dan di sisi lain juga Yogyakarta merupakan tempat kondusif untuk mengembangkan pemikiran keagamaan. Timbulnya pergeseran wacana keagamaan di Yogyakarta ini menarik untuk diamati. Oleh karena itu, perlu dilakukan studi yang lebih mendalam dan kom-

${ }^{1}$ Azyumardi Azra, "Islam di Tengah Arus Transisi Menuju Demokrasi", dalam Abdul Mu'in (ed), Islam di Tengab Arus Transisi, (Jakarta: Kompas, 2000). L ihat iuga Olivier Roy, Gagalnya Islam Politil, terj. Harimurti dan Qomaruddin SF, (Jakarta: Serambi, 1992), hal. 48.

${ }^{2}$ Andi Rakhmat dan Mukmad Najib, Gerakan Perlaweanan dari Masjid Kampus, (Surakarta: Purimedia, 2001). 
prehensif untuk melihat lebih jauh tentang pergeseran dinamika pemikiran dan organisasi Islam di Yogyakarta. Untuk lebih memfokuskan penelitian pada geliat pemikiran Islam yang ada di wilayah DIY. Pilihan ini setidaknya didasarkan pada alasan strategis sebagai berikut:

Pertama, lima kondisi di atas adalah apa yang terjadi pada dunia Islam Indonesia sekarang ini dan yang dapat dilihat dinamikanya di wilayah DIY.

Kedua, lebih dari itu DIY ternyata menjadi tempat pilihan untuk mendirikan markas-markas gerakan oposisi Islam yang berbasis politik, seperti: Hizbut Tabrir Indonesia (HTT), Jamaah Islamiah (I), Majelis Mijabidin Indonesia (MMI) dan sebagainya. Gerakan-gerakan ini lebih berakar pada fundamentalisme Islam.

Ketiga, maraknya pusat-pusat studi Islam maupun LSM-LSM yang mengusung diskursus keislaman baik yang berada di bawah universitas ataupun yang independent, misalnya PSI-UII, LKiS, JIMM dan sebagainya.

Tumbuh suburnya lembaga keagamaan yang dikenal eksklusif dan inklusif di wilayah DIY di atas sudah merupakan konsekuensi dari masyarakat Yogyakarta yang menghargai dan menghormati pluralitas, sehingga kedamaian dan kerukunan tetap terjaga di masyarakat. Motto "Jogja berhati nyaman" dan The City of Tolerance” inilah memberi ruang kepada semua masyarakat untuk mengekspresikan ide dan gagasan dengan bebas dalam kerangkan kedamaian dan kenyamanan.

Eksistensi kelompok-kelompok Islam yang ada di DIY tersebut tentu juga mempunyai pandangan atau wacana keislaman yang akan mereka sampaikan. Agar wacana tersebut lebih efektif untuk mencapai sasaran, maka media sosialisasi menjadi penting. Lahirnya berbagai macam buletin keislaman di DTY yang nota bene diterbitkan oleh masing-masing kelompok tersebut, dapat diasumsikan sebagai salah satu media sosialisasinya.

Kehadiran buletin Jum'at misalnya, yang selalu hadir pada hari Jum'at yang didistribusikan bagi pembaca yang melaksanakan shalat Jum'at, merupakan 'sasaran' paling efektif, karena beberapa pertimbangan:

1. Posisi pembaca yang sedang menunggu pelaksanaan rangkaian shalat Jum'at merupakan waktu kosong.

2. Shalat Jum'at merupakan aktivitas religius, sehingga kehadiran buletin Jum'at bagi pembaca secara implisit 'seakan' bagian ibadah dari aktivitas tersebut.

3. Buletin Jum'at dikemas pendek dan sederhana, sehingga tidak terkesan membosankan. 
4. Buletin sebagai media sosialisasi cetak yang mudah dilacak dokumentasinya.

Atas dasar tersebut buletin Jum'at pada gilirannya mempunyai kontribusi yang cukup strategis bagi pembaca dan perkembangan pemikiran di wilayah distribusinya.

Untuk memahami fenomena hadirnya berbagai buletin-buletin Jumat di berbagai komunitas keislaman di Yogyakarta tersebut, maka perlu diadakanpemetaan wacana keislaman yang tergambar baik secara eksplisit maupun implisit melalui isi muatan buletin-buletin jum'at yang tersebar di wilayah DIY. Sehingga dapat diketahui arah pemikiran setiap buletin dan mau dibawa kemana pemikiran pembaca terhadap pemahaman agamanya.

Dari latarbelakang di atas penelitian untuk mendapatkan gambaran tentang jenis-jenis wacana yang tertulis dalam buletin Jum'at yang ada di wilayah DIY perlu dilakukan. Keislaman yang dimaksud adalah ajaran Islam yang sudah dipraktekkan, dipelajari dan dipahami, sehingga sangat mungkin terjadi perbedaan cara seseorang dalam memahami dan cara mempraktekkan Islam itu sendiri satu dengan yang lainnya.

Selain wacana keagamaan di atas, juga untuk mengetahui dari sudut wacana itu sendiri yaitu pola penulisan yang digunakan, berupa susunan dan struktur penulisan. Dari sini, peneliti berusaha untuk mengetahui sudahkah pola penulisan buletin yang ada di DIY telah mengikuti susunan dan struktur yang baik, sehingga pembaca dengan mudah memahami pesan-pesan keagamaan yang ada di buletin.

Tujuan penelitian ini adalah untuk (a) memetakan dan mendiskripsikan tipologi wacana keislaman yang tergambar baik secara eksplisit maupun implisit melalui isi muatan buletin-buletin jum'at yang tersebar di wilayah DIY; dan (b) menjelaskan dan menganalisis elemen-elemen wacana melalui struktur penulisan yang digunakan dalam menyusun teks dan hubungannya dengan teks-teks dalam penerbitan berikutnya.

Dengan demikian secara teoritis-keilmuan, diperolehnya basis data buletin serta pemetaan tipologi wacana ke Islaman buletin-buletin jum'at yang beredar di wilayah DIY, minimal dalam kurun waktu tertentu; dan secara praktis-implementatif penelitian ini memberikan formulasi berupa rekomendasi kepada para pemangku kepentingan (stakebolder) yang lebih konkret. 


\section{B. Posisi dan Kerangka Teoritik}

Penelitian yang memetakan tipologi wacana keislaman di Indonesia khususnya di DIY melalui media buletin jum'at sejauh amatan peneliti belum pernah dilakukan. Kekosongan pembahasan tentang tema inilah antara lain yang membuat peneliti tertarik untuk melakukan telaah secara khusus.

Untuk membaca perkembangan wacana keislaman yang tergambar melalui media sosialisasi keislaman "buletin jum'at" tersebut, peneliti membagi dalam dua kategori yaitu pertama, pembacaan terhadap teks yang merujuk pada teori $R$. William Liddle. ${ }^{3}$ Kedua, wacana yang dikembangkan dalam memahami teks, yang kedua ini merujuk teorinya Fazlurrahman. ${ }^{4}$ Sedangkan alat analisis yang dipakai adalah analisis media teori Teun A. van Dijk. ${ }^{5}$

Analisis wacana dengan model van Dijk di atas paling banyak digunakan, sebab van Dijk mengelaborasi elemen-elemen wacana sehingga bisa diaplikasikan secara praktis. Model analisis yang dipakai van Dijk kerap disebut sebagai "kognisi sosial". Istilah ini sebenarnya diadopsi dari pendekatan lapangan psikologi sosial, terutama untuk menjelaskan struktur dan proses terbentuknya suatu teks. Penelitian atas wacana tidak cukup hanya didasarkan pada analisis teks semata, karena teks hanya hasil dari suatu praktik produksi yang harus juga diamati.

Melalui berbagai karyanya, van Dijk melihat suatu wacana terdiri atas berbagai struktur atau tingkatan yang masing-masing bagian saling mendukung. Struktur wacana yang dikemukanan van Dijk ini dapat digambarkan sebagai berikut:

\footnotetext{
${ }^{3} \mathrm{R}$. William Liddle, Leadersbip and Culture in Indonesian Politics, (Sydney: Asian Studies Association of Australia, 1996), hal. 75.

4L Lhat Fazlur Rahman, Islam; Challengges and Opportunity, Islam:past Influence and Present Challenge, eds. A.T. Welch dan P. Cachia. (Edinburgh: Edinbrgh University Press, 1979), hal. 315-325; Fazlur Rahman, Islam: Legacy and Contemporary Challenge, Islam in the Contemporary World, ed. CyriacK. Pullapilly, (Notre Dame: Cross Roads Books, 1980), hal. 402-415; Fazlur Rahman, Roots of Islamic NeoFundamentalism, Change and The Moslem World, ads. Philip H. Stoddard, et, al. (New York: Syracuse University Press, 1981), hal. 23-35.

${ }^{5}$ Alex Sobur, Analisis Teks Media, Suatu Pengantar untuk Analisis Wacana, Analisis Semiotik dan Analisis Framing, (Bandung: PT. Remaja Rosdakarya, 2001), hal. 73.
} 
Tabel 1

Pola Penulisan Struktur Teun Van Dijk

\begin{tabular}{|c|c|c|}
\hline Struilitur wacana & Hal yang diamati & Elemen \\
\hline Struktur Makro & $\begin{array}{l}\text { Tematik } \\
\text { (apa yang dikatakan) }\end{array}$ & Topik \\
\hline Superstruktur & $\begin{array}{l}\text { Skematik } \\
\text { (Bagaimana pendapat disusun } \\
\text { dan dirangkai) }\end{array}$ & Skema \\
\hline Struktur Mikro & $\begin{array}{l}\text { Semantik } \\
\text { (Makna yang ingin ditekankan dalam } \\
\text { teks berita) }\end{array}$ & $\begin{array}{l}\text { Latar, detail, maksud, } \\
\text { pra-anggapan, } \\
\text { nominalisasi. }\end{array}$ \\
\hline Struktur Mikro & $\begin{array}{l}\text { Sintaksis } \\
\text { (bagaimana pendapat disampaikan) }\end{array}$ & $\begin{array}{l}\text { Bentuk kalimat, } \\
\text { koherensi, kata ganti. }\end{array}$ \\
\hline Struktur Mikro & $\begin{array}{l}\text { Stilistik } \\
\text { (Pilihan kata apa yang dipakai) }\end{array}$ & Leksikon \\
\hline Struktur Mikro & $\begin{array}{l}\text { Retoris } \\
\text { (Bagaimana dan dengan cara apa } \\
\text { penekanan dilakukan) }\end{array}$ & $\begin{array}{l}\text { Grafis, metafora dan } \\
\text { ekspresi. }\end{array}$ \\
\hline
\end{tabular}

Dari teori tersebut di atas, peneliti tidak menggunakan seluruh struktur yang diungkapkan oleh van Dijk, yang diamati hanya tematik dan skematik saja, sebab kedua hal tersebut sangat berhubungan dengan wacana teks yang diteliti.

Kedua struktur ini adalah sebagai berikut:

(a) tematik, Sebuah tema bukan merupakan hasil dari seperangkat elemen yang spesifik, melainkan wujud-wujud kesatuan yang dapat dilihat di dalam teks atau bagi cara-cara yang dilalui agar beraneka kode dapat berkumpul dan koheren. Tematisasi merupakan proses pengaturan tekstual yang diharapkan pembaca sedemikian sehingga dapat memberikan perhatian pada bagian-bagian terpenting dari isi teks, yaitu tema. Jika menggunakan kerangka van Dijk, dalam teks akan didukung oleh beberapa sub-topik. Masing-masing sub-topik mendukung, memperkuat, bahkan membentuk topik utama. Gagasan van Dijk ini didasar pada pandangan ketika wartawan meliput suatu peristiwa dan memandang suatu masalah didasarkan pada suatu mental atau pikiran tertentu;

(b) skematik, struktur skematik memberikan tekanan: bagian mana yang didahulukan dan bagian mana yang bisa akhirkan sebagai strategi untuk menyembunyikan informasi penting. Upaya penyembunyian ini dilakukan dengan menempatkan bagian penting dibagian akhir agar terkesan kurang menonjol. Arti penting dari 
skematik adalah strategi untuk mendukung topik tertentu yang ingin disampaikan dengan menyusun bagian-bagian dengan urutan-urutan tertentu. Skematik memberikan penekanan mana yang didahulukan dan bagian mana yang bisa dikemudiankan sebagai suatu strategi.

\section{Metode Penelitian}

Penelitian ini dilaksanakan di wilayah DIY dengan mengambil tempat di masjidmasjid kampus dan masjid-masjid umum. Lokasi masjid tersebut adalah sebagai berikut:

Tabel 2

Daftar Masjid Lokasi Penelitian

\begin{tabular}{|c|c|c|c|c|}
\hline No & Masjid Kampus & Alamat & $\begin{array}{l}\text { Massid } \\
\text { Oinimim }\end{array}$ & Alamat \\
\hline 1 & $\begin{array}{l}\text { Masjid Universitas } \\
\text { Gajah Mada }\end{array}$ & Kampus UGM & $\begin{array}{l}\text { Masjid } \\
\text { Syuhada' }\end{array}$ & $\begin{array}{l}\text { Kotabaru, } \\
\text { Yogyakarta }\end{array}$ \\
\hline 2 & Masjid Ulil Albab & $\begin{array}{l}\text { Kampus } \\
\text { Universitas Islam } \\
\text { Indonesia }\end{array}$ & Masjid Agung & $\begin{array}{l}\text { Kauman, } \\
\text { Yogyakarta }\end{array}$ \\
\hline 3 & $\begin{array}{l}\text { Masjid UIN Sunan } \\
\text { Kalijaga }\end{array}$ & $\begin{array}{l}\text { Kampus } \\
\text { Universitas Islam } \\
\text { Negeri }\end{array}$ & $\begin{array}{l}\text { Masjid } \\
\text { Jogokaryan }\end{array}$ & Jogokaryan, Bant \\
\hline 4 & Masjid Muhajinin & $\begin{array}{l}\text { Kampus } \\
\text { Universitas Negeri } \\
\text { Yogyakarta }\end{array}$ & $\begin{array}{l}\text { Masjid } \\
\text { Sudirman }\end{array}$ & $\begin{array}{l}\text { Colombo, } \\
\text { Demangan, } \\
\text { Yogyakarta. }\end{array}$ \\
\hline
\end{tabular}

Pemilihan lokasi masjid di atas berangkat dari hasil survei pra penelitian yang menunjukkan bahwa di DTY masjid-masjid tersebut selain bangunan yang cukup besar dibanding yang masjid-masjid yang lain, masjid-masjid yang dipilih memiliki jumlah jamaah shalat Jum'at yang besar. Kemudian, masjid-masjid diatas juga dijadikan tempat penyebaran buletin jum'at lebih dari 3 buletin yang berbeda. Penelitian dilaksanakan pada bulan Januari 2006 sampai dengan bulan Mei 2007.

Metode pengumpulan data yang digunakan dalam penelitian ini yaitu metode dokumentasi kepustakaan yaitu dokumen-dokumen yang ada berupa lembaranlembaran buletin Jum'at dipelajari untuk memperoleh data dan informasi dalam penelitian ini. Pengambilan Buletin Jum'at tersebut diklasifikasikan dalam dua tempat, yaitu buletin yang ada di masjid-masjid kampus dan di masjid-masjid umum. Adapun Prosedur pengambilan data sebagai berikut: 
Bagan Prosedur Pengambilan data penelitian

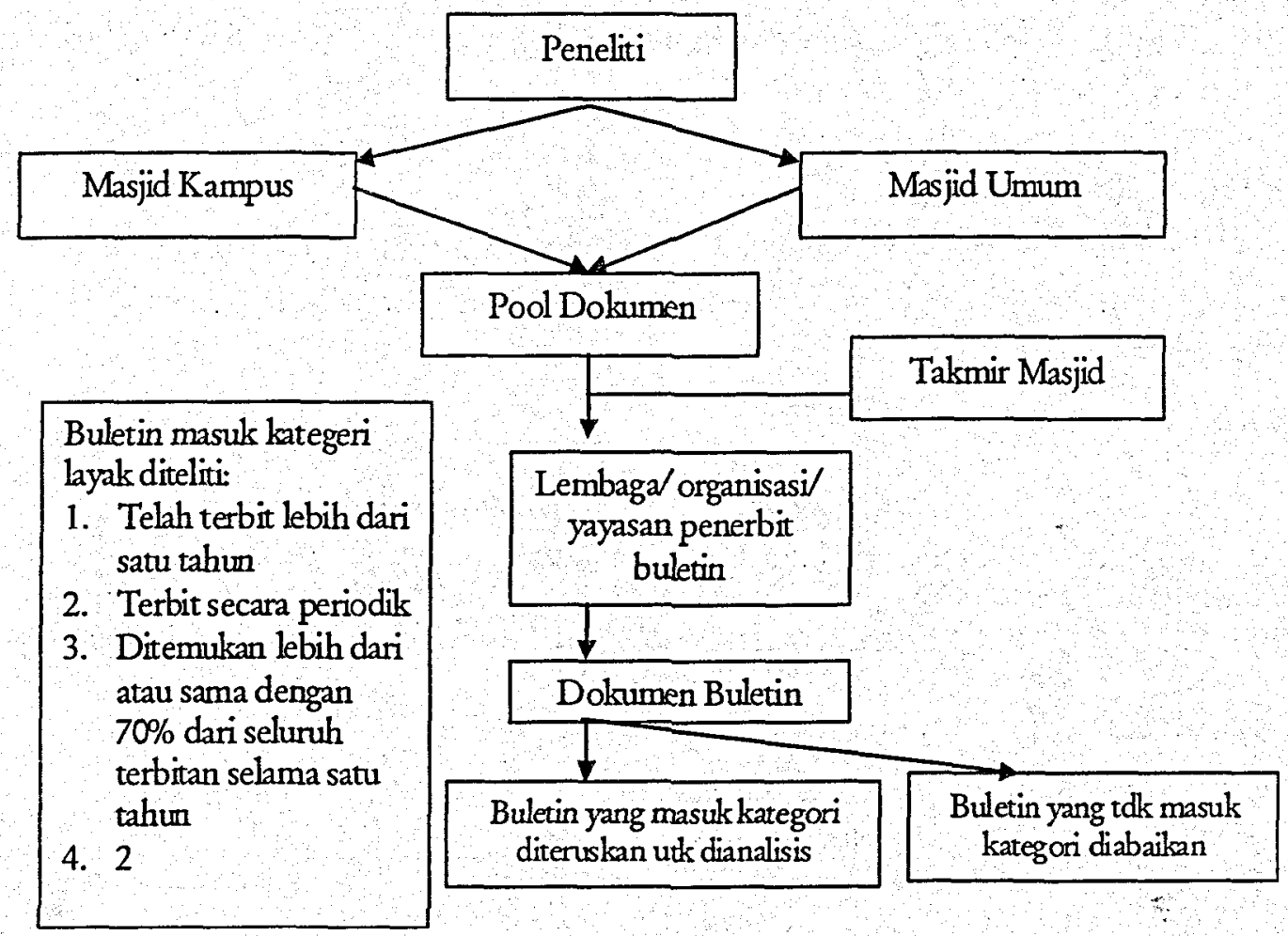

Penelitian ini adalah penelitian deskriptif eksploratif, dengan demkian teknik analisisnya adalah analisis deskriptif interpretatif. Setelah data terkumpul dari hasil pengumpulan data dan kegiatan penelitian, selanjutnya dilakukan interpretasi terhadap temuan tersebut. Analisis disajikan dalam bentuk tabel-tabel statistik.

Analisis di atas diharapkan dapat menggambarkan lebih mendalam tentang fenomena wacana keagamaan yang terekam dalam bulletin-buletin Jumat yang terbit atau dikelola oleh takmir masjid atau juga komunitas keislaman tertentu. yang diteliti. ${ }^{6}$ Analisis diskriptif interpretatif ini digunakan untuk menganalisis data yang diperoleh untuk menjawab rumusan masalah yang pertama tentang arah kecenderungan wacana keislaman yang tertulis dalam buletin-buletin Jum'at di wilayah DIY.

Kemudian untuk analisis wacana, yaitu studi tentang struktur pesan dalam komunikasi atau telaah mengenai aneka fungsi (fragmatik) bahasa, penggunaan bahasa dalam kesinambungan atau untaian wacana. Tanpa konteks, tanpa hubungan-hubung-

${ }^{6}$ Masri Singarimbun dan Sofian Effendi, Metode Penelitian Survey, (Jakarta: LP3ES, 1995). 
an wacana yang bersifat antar kalimat dan suprakalimat maka akan sukar berkomunikasi dengan tepat satu sama lain. Analisis wacana lahir dari kesadaran bahwa persoalan yang terdapat dalam komunikasi bukan terbatas pada penggunaan atau bagian kalimat, fungsi ucapan, tetapi juga mencakup struktur pesan yang lebih komplek dan inheren yang disebut wacana.

Dari segi analisisnya, ciri dan sifat wacana di atas dapat dikemukakan sebagai berikut:

1. Analisis wacana membahas kaidah memakai bahasa di dalam mesyarakat (rule of use).

2. Analisis wacana merupakan usaha memahami makna turunan dalam konteks, teks, dan situasi.

3. Analisis wacana merupakan pemahaman rangkaian tuturan melalui interpretasi semantik.

4. Analisis wacana berkaitan dengan pemahaman bahwa dalam tindak berbahasa (what is said from what is done).

5. Analisis wacana diarahkan kepada masalah memakai bahasa secara fungsional (functional use of language).

Dalam teknis analisis, peneliti menggunan double cross-check, yaitu antara hasil analisis satu anggota peneliti dengan anggota peneliti yang lain dibandingkan untuk memastikan apakah ada perbedaan yang cukup signifikan antara keduanya. Hasil perbandingan menunjukkan tidak ada perbendaan yang menonjol antara hasil analisis kedua anggota peneliti. Proses ini dilakukan untuk meminimalisir subyektifitas peneliti terhadap obyek yang diteliti.

Adapun Indikator yang dipakai untuk analisis terhadap buletin adalah merujuk pada teori R. William Liddle dan teori Fazlur Rahman. Kemudian peneliti memberikan batasan bila teks buletin yang sedang dianalsis telah memenuhi tiga atau lebih dari ciri-ciri yang disebutkan oleh teori Liddle dan Fazlur Rahman tersebut.

Sedangkan untuk mengukur indikator pola penulisan, peneliti menggunakan teori Teun A. van Dijk. Dengan batasan bila ciri-ciri yang telah disebutkan oleh Van Dijk secara umum ditemukan dalam teks buletin. Ciri-ciri tematik menurut teori ini adalah teks didukung oleh beberapa sub-topik. Masing-masing sub-topik mendukung, memperkuat, bahkan membentuk topik utama. Gagasan van Dijk ini didasarkan

${ }^{7}$ Alex Sobur. (2001), Analisis Teks..., hal. 48-50. 
pada pandangan ketika wartawan meliput suatu peristiwa dan memandang suatu masalah didasarkan pada suatu mental atau pikiran tertentu. Kognisi atau mental ini secara jelas dapat dilihat dari topik yang dimunculkan dalam berita. Karena topik disini dipahami sebagai mental atau kognisi wartawan, tidak mengherankan jika semua elemen dalam berita mengacu dan mendukung topik dalam berita.

Kemudian analisa wacana yang skematik menurut teori ini adalah kalau topik menunjukkan makna umum dari suatu wacana, maka struktur skematis atau superstruktur menggambarkan bentuk dari suatu teks. Bentuk wacana umum itu disusun dengan sejumlah kategori atau pembagian umum seperti pendahuluan, isi, kesimpulan, pemecahan masalah, penutup, dan sebagainya. Skematik mungkin merupakan strategi dari komunikator untuk mendukung makna umum dengan memberikan sejumlah alasan pendukung. A pakah informasi penting disampaikan diawal atau pada kesimpulan bergantung pada makna yang didistribusikan dalam wacana. Dengan kata lain, struktur skematik memberikan tekanan: bagian mana yang didahulukan dan bagian mana yang dapat diakhirkan sebagai strategi untuk menyembunyikan informasi penting. Upaya penyembunyian ini dilakukan dengan menempatkan bagian penting dibagian akhir agar terkesan kurang menonjol.

\section{Temuan Penelitian dan Analisis}

Hasil penelusuran Buletin di delapan masjid Dr, ditemukan ada 12 buletin Jum'at, yaitu:

\section{Tabel 3}

Buletin Jum'at yang tersebar di wilayah DIY

\begin{tabular}{|c|c|c|}
\hline No & Wuletin & 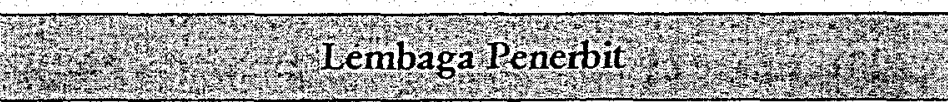 \\
\hline 1. & Risalah Jum'at & $\begin{array}{l}\text { Majlis Tabligh dan Dakwah Khausus Pimpinan Wilayah } \\
\text { Muhammadiyah Yogyakarta }\end{array}$ \\
\hline 2. & Al- Rasikh & LPPAI-UII \\
\hline 3. & Ikhlas News & Institute of Sharia Economics studies \\
\hline 4. & Syari'atuna & Prodi Fukum Islam, FIAI-UII \\
\hline 5 . & Iqtisoduna & Prodi Ekonomi Islam FIAI-UII \\
\hline 6. & Al-Lu'luk & PP.UII \\
\hline 7. & Al-Ikhtilaf & LKIS \\
\hline 8. & Al-I'tishom & Forum Silaturrahmi Takmir Masjid se-Maguwóharjo \\
\hline 9. & Tarbawi & Prodi Tarbiyah FIAI \\
\hline 10. & At-Tauhid & Lembaga Bimbingan Islam Al Atsary Yogyakarta \\
\hline 11. & Media Dakwah & \\
\hline 12. & Muchever-21 & \\
\hline
\end{tabular}


Tidak semua buletin yang ditemukan tersebut di atas dapat dilanjutkan untuk diteliti. Peneliti menggunakan batasan atau kategori buletin mana yang dapat diteruskan untuk dijadikan obyek penelitian. Kategori tersebut adalah: telah terbit lebih dari satu tahun; terbit secara periodik; dan ditemukan lebih dari atau sama dengan $70 \%$ dari seluruh terbitan selama satu tahun.

Dari buletin yang ditemukan di atas ternyata yang masuk kategori untuk diteliti hanya 6 (enam) buletin, sisanya merupakan buletin yang tidak memenuhi kategori tersebut diatas. Sedangkan buletin-buletin yang tidak masuk kategori untuk diteliti adalah buletin Syariatuna, Iqtisoduna, Tarbawi, Media Dakwab, al-Luk-luk dan Muchever-21.

Secara umum buletin-buletin yang tersebar di Yogyakarta memiliki kecenderungan sebagai berikut:

\section{Tabel 4}

Pola Penulisan Buletin Jum'at di wilayah DIY

\begin{tabular}{|c|c|c|c|c|c|c|}
\hline No & Builetin & Tematik & $\begin{array}{l}\text { TIdak } \\
\text { Tematik }\end{array}$ & Semanth & $\begin{array}{l}\text { Thank } \\
\text { Semanth }\end{array}$ & $\begin{array}{l}\text { TIdak } \\
\text { Keduanya, } \\
\text { Kand }\end{array}$ \\
\hline 1 & Alikhtilaf & 28 & 19 & 33 & 14 & 7 \\
\hline 2 & Alrasikh & 32 & 21 & 24 & 29 & 1 \\
\hline 3 & Al I'tishom & 22 & 17 & 17 & 22 & 0 \\
\hline 4 & Al ikhlas & 19 & 26 & 26 & 19 & 1 \\
\hline 5 & At-Tauhid & 46 & 4 & 31 & 19 & 1 \\
\hline 6 & $\begin{array}{l}\text { Risalah } \\
\text { Jum'at }\end{array}$ & 42 & 8 & 26 & 24 & 1 \\
\hline & Total & 189 & 95 & 157 & 127 & 11 \\
\hline
\end{tabular}

Dari 284 tema dari seluruh buletin yang ditemukan terdapat $189(66.5 \%)$ tema yang telah mengikuti pola penulisan tematik dan $154(55.2 \%)$ tema yang telah mengikuti pola skematik. Temuan tersebut masih membuktikan bahwa secara umum buletin yang tersebar di DIY pada umumnya sudah baik secara tematik dan skematik.

Artinya bahwa tulisan telah tulisan disusun dari lead, paragraf-paragraf, isi, dan penutup (paragraf akhir) kesemuanya telah memperkuat tema tulisan. Argumenargumen yang disampaikan pada tiap paragraf memperjelas dan memperkuat paragraf yang lain sehingga tulisan adakalanya tidak keluar dari tema yang ditulis.

Kemudian, tulisan juga telah disusun secara rapi, terstruktur dan umumnya ditutup dengan kesimpulan akhir yang merupakan inti yang ingin disampaikan dan tulisan dikuatkan sub bahasan-sub bahasan sebagai pengembangan dari inti tulisan dan ditutup dengan kesimpulan. 
Kemudian dari analisa keagamaan, pada umumnya 6 (enam) buletin yang diteliti memiliki kecenderungan sebagai berikut:

\section{Tabel 5}

Kecenderungan Wacana Buletin di wilayah DIY

\begin{tabular}{|c|l|l|l|}
\hline No & B Buletin & \multicolumn{2}{|c|}{ Kecenderungan } \\
\cline { 3 - 4 } & Al-Ikhtilaf & Substansialis & Neo-modernis \\
\hline 2 & Al-Rasilh & Substansialis & $\begin{array}{l}\text { Revivalisme } \\
\text { Pra-Modem }\end{array}$ \\
\hline 3 & Al-I'tishom & Substansialis & Neo-Revivalisme \\
\hline 4 & Al-Tauhid & Tekstualis & $\begin{array}{l}\text { Revivalisme } \\
\text { Pra-Modem }\end{array}$ \\
\hline 5 & Risalah Jum'at & Substansialis & $\begin{array}{l}\text { Revivalisme } \\
\text { Pra-Modern }\end{array}$ \\
\hline 6 & Ilkhlas News & Substansialis & Neo-Revivalisme \\
\hline
\end{tabular}

Dilihat dari cara pembacaan teks dijumpai ada 5 buletin dari 6 buletin yang diteliti, artinya pada umumnya buletin di DTY lebih cenderung beraliran substansialis, yaitu tidak terkungkung semata-mata oleh nilai normatif, sehingga lebih leluasa memahami teks dan tradisi Islam secara terbuka dan dinamis. Kemudian teks dan tradisi Islam tidak dijadikan sebagai sistim kredo yang beku, sehingga tidak menutup peluang bagi interpretasi baru sesuai dengan perkembangan kontemporer.

Sedangkan dalam pemikiran substansialis, teks-teks normatif itu akan lebih bermakna bila dilakukan penafsiran ulang sesuai dengan dinamika perkembangan masyarakat, karena pemahaman terhadap teks tak bisa lepas dari pemahaman terhadap konteks. Kemudian, isi jauh lebih dipentingkan dari bentuk atau label, sehingga berusaha menjauhi hal-hal yang bersifat simbolis, legal formalistis semata. Dan terakhir, berusaha agar nilai-nilai universal Islam seperti keadilan sosial, demokrasi, toleransi dan egalitarianisme dapat diwujudkan dalam kehidupan masyarakat untuk dijadikan etika sosial.

Kemudian; wacana yang dikembangkan, dari 6 buletin yang ada di DIY, 3 buletin diantaranya cenderung mengarah pada Neo-Revivalisme dan Revivalisme PraModernis, yaitu adanya keprihatinan yang mendalam tentang degradasi sosio moral umat Islam dan usaha mengubahnya, kemudian adanya himbauan untuk kembali kepada Islam sejati dan mengenyahkan tahayul-tahayul yang ditanamkan oleh bentuk-bentuk sufisme populer dan himbauan mengenyahkan corak predeterministik. yaitu imbauan melaksanakan pembaharuan ini lewat jihad. 


\section{E. Penutup}

Sebagai penutup dan akhir dari tulisan ini perlu dikemukakan kesimpulankesimpulan sebagai berikut:

1. Bahwa kecenderungan wacana keislaman yang dimuat dalam buletin pada umumnya adalah substansialis-neomodernis dan revivalis pra modern ini masih perlu kajian lebih mendalam, sebab berdasarkan teori yang sudah dijelaskan Liddle di atas, justru yang muncul pada era reformasi adalah tekstualis, kenapa justru ditemukan dalam media buletin adalah substansialis-neomodernis dan revivalis pramodern. Perlu ada penelitan wacana Islam dengan obyek yang berbeda sehingga temuan ini dapat diperkuat atau justru sebaliknya.

2. Bahwa tulisan buletin yang ada kecenderungan tidak terstruktur secara tematis dan skematis membuat pembaca awam cukup sulit memahami pesan-pesan buletin, sehingga perlu ada penyampaian hasil penelitian ini kepada pengelola buletin agar ada perbaikan struktur tulisan, sehingga kaidah jurnaslistik tetap terjaga, wal hasil, tidak menutup kemungkinan mempermudah komunikasi pembaca dan penyampai pesan dalam buletin.

Hasil penelitian ini sangat penting bagi pemerintan daerah untuk kepentingan pembinaan dan pemetaan pemikiran keislaman di wilayah DIY yang selanjutnya dapat ditindaklanjuti dalam bentuk program riel bagi penerbit buletin.

\section{DAFTAR PUSTAKA}

Azhar, Muhammad. (2006), Tipologi Pemikiran Modern dan Posmodern, dalam Suara Muhammadiyah no 11/Th ke 91, 1-15 Juni 2006.

Azra, Azyumardi. (2000); Islam di Tengah Arus Transisi Menuju Demokrasi, dalam Abdul Mu'in (ed.), Islam di Tengah Arus Transisi. Jakarta: Kompas, 2000.

Liddle, R. William. (1996), Leadership and Culture in Indonesian Politics, Sydney: Asian Studies Association of Australia.

Rahman, Fazlur. (1979). Islam; Challengges and Opportunity, Islam:past Influence and Present Challenge, eds. A.T. Welch dan P. Cachia. Edinburgh: Edinburgh University Press. (1980), Islam: Legacy and Contemporary Challenge, Islam in the Contemporary World, ed. Cyriac K.Pullapilly. Notre Dame: Cross Roads Books. 
14 Millab Vol. IX, No. 1, Agustus 2009

_- (1981), Roots of Islamic Neo-Fundamentalism, Change and The Moslem World, eds. Philip H. Stoddard, et, al. New York: Syracuse University Press.

Rakhmat, Andi dan Mukmad Najib. (2001), Gerakan Perlaweanan dari Masid Kampus. Surakarta: Purimedia.

Ridwan, Nur Khalik. (2004), Santri Baru: Pemetaan, Wacana Ideologi, dan Kritik. Yogyakarta: Gerigi Pustaka.

Roy, Olivier. (1992), Gagalnya Islam Politik, terj. Harimurti dan Qomaruddin SF, Jakarta: Serambi.

Sobur, Alex. (2001), Analisis Teks Media, Suatu Pengantar untuk Analisis Wacana, Analisis Semiotik dan Analisis Framing, Bandung: PT. Remaja Rosdakarya.

Singarimbun, Masri dan Sofian Effendi. (1995), Metode Penelitian Survey, Jakarta: LP3ES. 